\title{
Endogenous ways to stimulate brown adipose tissue in humans
}

Citation for published version (APA):

Broeders, E., Bouvy, N. D., \& van Marken Lichtenbelt, W. D. (2015). Endogenous ways to stimulate brown adipose tissue in humans. Annals of Medicine, 47(2), 123-132.

https://doi.org/10.3109/07853890.2013.874663

Document status and date:

Published: 01/01/2015

DOI:

10.3109/07853890.2013.874663

Document Version:

Publisher's PDF, also known as Version of record

Document license:

Taverne

Please check the document version of this publication:

- A submitted manuscript is the version of the article upon submission and before peer-review. There can be important differences between the submitted version and the official published version of record.

People interested in the research are advised to contact the author for the final version of the publication, or visit the DOI to the publisher's website.

- The final author version and the galley proof are versions of the publication after peer review.

- The final published version features the final layout of the paper including the volume, issue and page numbers.

Link to publication

\footnotetext{
General rights Owners
rights.

- You may freely distribute the URL identifying the publication in the public portal. please follow below link for the End User Agreement:

www.umlib.nl/taverne-license

Take down policy

If you believe that this document breaches copyright please contact us at:

repository@maastrichtuniversity.nl

providing details and we will investigate your claim.
}

Copyright and moral rights for the publications made accessible in the public portal are retained by the authors and/or other copyright owners and it is a condition of accessing publications that users recognise and abide by the legal requirements associated with these

- Users may download and print one copy of any publication from the public portal for the purpose of private study or research.

- You may not further distribute the material or use it for any profit-making activity or commercial gain

If the publication is distributed under the terms of Article $25 \mathrm{fa}$ of the Dutch Copyright Act, indicated by the "Taverne" license above, 


\section{Annals of Medicine}

\section{Endogenous ways to stimulate brown adipose tissue in humans}

\section{Evie Broeders, Nicole D. Bouvy \& Wouter D. van Marken Lichtenbelt}

To cite this article: Evie Broeders, Nicole D. Bouvy \& Wouter D. van Marken Lichtenbelt (2015) Endogenous ways to stimulate brown adipose tissue in humans, Annals of Medicine, 47:2, 123-132, DOI: 10.3109/07853890.2013.874663

To link to this article: https://doi.org/10.3109/07853890.2013.874663

曲 Published online: 13 Feb 2014.

Submit your article to this journal $\sqrt{3}$

LII Article views: 1278

Q View related articles ¿

$\bigodot_{\text {CrossMark }}$ View Crossmark data

4 Citing articles: 5 View citing articles $\square$ 


\title{
Endogenous ways to stimulate brown adipose tissue in humans
}

\author{
Evie Broeders ${ }^{1,2}$, Nicole D. Bouvy ${ }^{2} \&$ Wouter D. van Marken Lichtenbelt ${ }^{1}$ \\ 'Department of Human Biology, NUTRIM - School for Nutrition, Toxicology and Metabolism, Maastricht University Medical Centre, \\ Maastricht, the Netherlands, and ${ }^{2}$ Department of Surgery, Maastricht University Medical Centre, Maastricht, the Netherlands
}

\begin{abstract}
Obesity is the result of disequilibrium between energy intake and energy expenditure (EE). Successful long-term weight loss is difficult to achieve with current strategies for the correction of this caloric imbalance. Non-shivering thermogenesis (NST) in brown adipose tissue (BAT) is a possible therapeutic target for the prevention and treatment of obesity and associated metabolic diseases. In recent years, more knowledge about the function and stimulation of bat has been obtained. The sympathetic nervous system (SNS) is currently seen as the main effector for brown fat function. Also, interplay between the thyroid axis and SNS plays an important role in BAT thermogenesis. Almost daily new pathways for the induction of BAT thermogenesis and 'browning' of white adipose tissue (WAT) are identified. Especially the activation of BAT via endogenous pathways has received strong scientific attention. Here we will discuss the relevance of several pathways in activating BAT and their implications for the treatment of obesity. In this review we will focus on the discussion of the most promising endocrine and paracrine pathways to stimulate BAT, by factors and pathways that naturally occur in the human body.
\end{abstract}

Key words: Anti-obesity therapy, beige adipocytes, brown adipose tissue, endocrine factors, non-shivering thermogenesis, paracrine factors, UCP1

\section{Introduction}

Changed dietary habits and modern technological developments, which contributed to a sedentary lifestyle, have led to a worldwide increase in the incidence of overweight and obesity, which has now reached epidemic proportions in the Western world (1). The development of obesity results from a prolonged disequilibrium in the energy balance with energy intake exceeding energy expenditure, leading to storage of excess calories as fat, both subcutaneously and intra-abdominally. In the past decades obesity and its accompanying metabolic diseases have emerged to be the second most common preventable cause of death in Western society. The present therapeutic options for correcting the caloric imbalance causing obesity include both therapies focusing on decreasing energy intake and exercise programs to enhance energy expenditure. However, successful long-term weight loss defined as losing
Key message

- The interplay between the different pathways described in this review points towards the need to target not only specific factors but to take into account these interactions.

$10 \%$ of the initial body weight and maintaining the loss for at least one year is only achieved in around $20 \%$ after these programs. Due to the ineffectiveness of the existing treatments, there is a need to explore other strategies. Lately, prescription weight loss medication and bariatric surgery have received strong scientific attention in treatment of (morbid) obesity. Furthermore, coldstimulated adaptive thermogenesis in brown adipose tissue (BAT) is suggested as a possible therapeutic target for the prevention and treatment of obesity and associated metabolic diseases (2).

In recent years, more knowledge about the function and induction of BAT has been obtained. The sympathetic nervous system (SNS) is currently seen as the main effector for brown fat function. Also, interplay between the thyroid axis and SNS has been identified to play an important role in BAT thermogenesis. Studies both in animals and in man show different ways in which BAT thermogenesis can be regulated and stimulated. Here we will discuss the relevance of several pathways for activating BAT, and their implications for the treatment of obesity. In this review of both human and experimental studies we will discuss several pathways for endogenous BAT activation. We will focus on the discussion of the most promising endocrine and paracrine pathways in humans to stimulate BAT, via factors or pathways that naturally occur in the human body.

\section{BAT: function and detection}

\section{BAT function and regulation of thermogenesis in BAT}

The main function of white adipose tissue (WAT) is energy storage; the cells have large fat droplets and minimal numbers of mitochondria. Brown adipose tissue (BAT), on the other hand, is specifically designed to generate heat, with cells containing 
multiple fat vacuoles and numerous mitochondria, giving the tissue its brown color. The functional difference between the two types of fat found in the human body is highlighted by the high sympathetic innervation and vascularization of BAT.

BAT is widely known to have the ability to burn off excess energy in a process called mitochondrial uncoupling. This unique response is facilitated by a mitochondrial membrane protein called UCP1 (uncoupling protein one, thermogenin), which is used as a marker for brown adipose tissue. UCP1 has the ability to uncouple the normal respiration chain, utilizing the proton gradient across the mitochondrial membrane to generate heat in response to cold (non-shivering thermogenesis (NST)) instead of using it for adenosine triphosphate (ATP) production (3), profoundly increasing energy expenditure. Stimulation of this coldinduced, UCP1-dependent increase in energy expenditure might be beneficial in the treatment of obesity and associated metabolic diseases.

Recent in vitro studies have shown that the quantity and functional activity of brown adipocytes can be regulated. Brown adipocytes and skeletal muscle cells arise from myf5 progenitors. Several transcriptional coactivators, such as PRDM16 (4), PGC1 $\alpha$ (peroxisome proliferator-activated receptor gamma coactivator 1-alpha) (5) and growth factors like BMP7 (bone morphogenetic protein 7) have been identified that can influence the differentiation process of pre-adipocytes into white or brown phenotypes (4). Stimulation of white fat with these factors has been identified to stimulate the development of active thermogenic brown-like adipocytes within white fat depots. These cells are not typical brown adipocytes, but they form a particular type of adipocytes, named 'beige', 'brite', or 'brown-in-white' adipocytes.

Besides the 'browning' of white adipose tissue, BAT can also be recruited. Recent work has shown that a 10-day acclimation period leads to increased energy expenditure and increased glucose uptake in typical BAT locations, indicating BAT or brite recruitment in adult humans (6). This too might be of great importance in targeting obesity in the future, as adjustments of ambient temperature in everyday life might have beneficial effects on BAT presence and, if environment temperatures are low enough, on thermogenesis in BAT.

\section{Visualization of BAT using [ ${ }^{18}$ F]FDG PET-CT and cold exposure}

Functional BAT in adult humans was discovered by $2-{ }^{18} \mathrm{~F}$ fluoro-D-glucose positron-emission-tomography-and-computertomography ([ $\left.{ }^{18} \mathrm{~F}\right]$ FDG PET-CT) fusion imaging, used in nuclear medicine to depict glucose uptake for tumor diagnosis.

In the past decades $\left[{ }^{18} \mathrm{~F}\right] \mathrm{FDG}$ uptake in the neck and supraclavicular regions, which could not be explained by normal structures or pathology of oncologic origin, was regularly seen during this routine oncologic imaging. These findings soon led to the discovery that the uptake is mapping areas of adipose tissue in the supraclavicular and neck area and is related to mild cold conditions in the room during administration of the tracer. In 2003 a total of 863 PET-CT scans were evaluated. Non-pathologic $\left[{ }^{18} \mathrm{~F}\right]$ FDG activity was observed in adipose tissue in the neck and shoulder region, axillae, mediastinum, and perirenal regions (7). Tissue biopsies from PET-active supraclavicular tissue confirmed BAT presence, responsible for the glucose uptake $(8,9)$. Since this discovery the interest in the possibilities of this thermogenic organ increased exponentially. Because of its high heat production capacity in rodents, the stimulation of BAT in man is seen as an anti-obesity target (3).

Although $\left[{ }^{18} \mathrm{~F}\right]$ FDG PET-CT is currently the most used technique for depicting metabolically active BAT in humans, there are significant limitations to this method. Mainly the radiation exposure associated with PET-CT imaging precludes repeated imaging of BAT in healthy young subjects (10). Moreover, $\left[{ }^{18} \mathrm{~F}\right]$ FDG PET-CT scanning visualizes glucose uptake, but does not provide information on the uptake of fatty acids, the most important alternative energy source, and oxidative metabolism. Fatty acid uptake in BAT can be visualized by using a fatty acid tracer, like ${ }^{18} \mathrm{~F}$-fluoro-thiaheptadecanoic acid ( $\left.{ }^{18} \mathrm{FTHA}\right)$, instead of a glucose tracer. BAT visualization by means of ${ }^{123} \mathrm{I}$-MIBG SPECT$\mathrm{CT}$ is currently being evaluated by several groups. A recent study showed that ${ }^{123}$ I-MIBG SPECT-CT and $\left[{ }^{18}\right.$ F]FDG PET-CT identify the same anatomic regions as active BAT. Also, there was a strong correlation between the magnitudes of BAT activity measured by both techniques (11). Possibly, in the future ${ }^{123}$ I-MIBG SPECT-CT could be used as a visualization method for BAT. Another attractive method for the study of BAT is MRI. The main advantage of MRI over PET-CT scanning is that MRI does not deliver mutagenic radiation (12). Also, with MRI a more reliable distinction between BAT and WAT can be made based on water content of the tissue, which is $50 \%$ and $10 \%$, respectively (13).

Cold exposure is an important activator of BAT (3). Besides the direct effect of cold exposure on BAT activity, animal studies have also shown that there is a positive effect of long-term cold exposure on NST and BAT recruitment. Recently two studies in humans showed results in line with these earlier findings in rodents and primates. In one study healthy subjects were exposed to mild cold environment $\left(15-16^{\circ} \mathrm{C}\right)$ for up to 6 hours a day, for 10 consecutive days, after which they showed a significant increase in brown adipose tissue activity (upper body BAT activity $2.4 \pm 0.7$ SUV (standard uptake value) mean before cold acclimation versus $2.8 \pm 0.5$ SUV mean after cold acclimation, $P<0.01)$ in parallel with increased energy expenditure $(10.8 \% \pm 7.5 \%$ before cold acclimation versus $17.8 \% \pm 11.1 \%$ after cold acclimation, $P<0.05$ ). Furthermore, cold tolerance seemed to increase in these subjects during the course of the cold acclimation period, as subjects tended to report more comfort and less shivering towards the end of the cold acclimation period (6). In the second study healthy adults were subjected to a daily 2 -hour cold exposure at $17^{\circ} \mathrm{C}$ for 6 weeks. This cold acclimation protocol resulted in an increase in BAT activity from $2.46 \pm 0.40$ to $3.89 \pm 0.64 \mathrm{SUV}(P=0.01)$ accompanied with a significant increase in energy expenditure (EE) (14).

A recent paper showed that a minimal decrease in ambient temperature already leads to induction of BAT activity. Subjects were exposed to a temperature of $19^{\circ} \mathrm{C}$, after which an $\left[{ }^{18} \mathrm{~F}\right] \mathrm{FDG}$ PET-CT scan was performed. BAT activity increased significantly and was positively correlated with individual NST responses (15).

\section{Endogenous ways for activation of BAT in humans}

\section{Sympathetic stimulation (SNS/catecholamines)}

Despite the many hypotheses regarding the most effective mechanisms for BAT activation, there is a general consensus that BAT is under direct control of the sympathetic nervous system (SNS). Following cold exposure, BAT is stimulated by the SNS to generate heat, most likely through temperature-sensitive neurons located in the skin (16). Thermogenesis in BAT is regulated by responses from these neurons, which are mediated and controlled in the preoptic area of the hypothalamus. Within this central network controlling BAT activation, medullary sympathetic premotor neurons seem to play a vital role. GABA (gamma-aminobutyric acid)-ergic neurons in this hypothalamic area are activated, which causes disinhibition of neurons in the dorsomedial hypothalamus, 
which project to the medulla oblongata, where the projections are conveyed into sympathetic stimuli. The consequential release of norepinephrine at the nerve endings causes BAT activation, due to binding to $\beta$-adrenergic receptors on the cell surface of BAT cells, which induces expression of uncoupling protein-1 (16).

The level of heat production in BAT depends mainly on the degree of activation of BAT sympathetic nerves, the extent of subsequent norepinephrine release, and the intensity of binding of released norepinephrine to the adrenergic receptors. Adrenergic stimulation of BAT increases intracellular cAMP (cyclic adenosine monophosphate) release and activates protein kinase $\mathrm{A}$ (PKA), leading to the expression of thermogenic genes and transcriptional regulators as well as activation of fueling enzymes for mitochondrial oxidation of lipids (17). In addition, the subtype of the $\beta$-receptor that is targeted is essential for the extent of BAT thermogenesis accomplished, with the $\beta 3$-receptor subtype being the most effective activator for BAT thermogenesis (3).

Animal viral tracing studies have shown that the neurons within the spinal cord, forebrain, and brainstem play a key role in controlling BAT thermogenesis (18). Especially the medulla is of importance, as this area contains one or more of the following markers that are known to influence BAT sympathetic neurons: the vesicular glutamate receptor 3 (VGLUT3), serotonin (5-HT) or tryptophan hydroxylase, which is a synthetic enzyme for serotonin, and glutamic acid decarboxylase-67 (GAD-67), a specific marker for GABA-ergic neurons (19).

Serotonergic agents are known for their potential to affect metabolism. However, little knowledge about the neural pathways in which serotonin (5-hydroxytryptamine (5-HT)) affects energy expenditure has been obtained. Recently, involvement of the glutamate and serotonin system in BAT sympathetic nerve activity was demonstrated in a rat model. After activation of $5-\mathrm{HT}_{1 \mathrm{~A}} / 5-$ $\mathrm{HT}_{7}$ receptors, by direct injection of a receptor agonist into the spinal cord, sympathetic nerve activity outflow to BAT increased. Furthermore, 5-HT receptor stimulation potentiates BAT response to glutamate (20). This is demonstrated in recent studies, in which combined activation of the serotonin and glutamate receptors lead to a synergistic effect of the two, markedly increasing sympathetic activation of BAT (21).

The importance of the SNS in BAT activation and function in humans is emphasized in recent studies. Pheochromocytoma patients, characterized by elevated plasma levels of catecholamine due to secretion of norepinephrine and epinephrine by a neuroendocrine adrenal gland tumor, showed high BAT activity on $\left[{ }^{18} \mathrm{~F}\right]$ FDG PET-CT imaging, which disappeared after resection of the tumor (22). In contrast, blocking of adrenergic receptors with a receptor antagonist (propranolol, non-selective $\beta$-antagonist) completely diminished FDG uptake in BAT areas, suggesting the involvement of these adrenergic receptors in BAT activation in humans (23). Very few studies have investigated the effects of SNS stimulation on BAT activity. A recent study from 2012 showed no stimulatory effect of the sympathomimetic ephedrine, which was given in a single intramuscular dose of $1 \mathrm{mg} / \mathrm{kg}$ bodyweight, on BAT activity. SUV maximum values remained at baseline level after administration of ephedrine (24). Another study in humans, in which the non-selective $\beta$-adrenergic agonist isoprenaline was used to mimic $\beta$-adrenergic SNS activity, showed similar results. After intravenous administration of incremental doses of isoprenaline $(6,12$, and $24 \mathrm{ng}$ per $\mathrm{kg}$ fat-free mass) in 9 out of the 10 subjects no detectable $\left[{ }^{18} \mathrm{~F}\right] \mathrm{FDG}$-uptake in BAT regions was observed, whereas cold stimulation in the same subjects did, as expected, lead to an increased BAT activity compared to baseline. However, this unexpected finding is possibly due to insufficiently high systemic concentrations of isoprenaline, much lower than at the nerve ending, leading to insufficient triggering of $\beta$-receptors on brown adipocytes (25). Furthermore, adrenergic agents such as ephedrine and isoprenaline are non-selective $\beta$-agonists. Stimulation of the SNS by administration of these agents will lead to $\beta 1$-mediated stimulation of the cardiovascular system (increased blood pressure and heart rate), whereas for BAT stimulation the $\beta 3$-receptor seems to be the main effector for thermogenesis (22), as suggested from studies in which BAT activity after $\beta 3$ stimulation was compared with BAT activity after norepinephrine administration (3). Furthermore, blocking of the $\beta 1$ - and $\beta 2$-adrenergic receptors through administration of propanolol decreases BAT activity under thermoneutral circumstances, demonstrating the involvement of $\beta$-adrenergic receptors in BAT thermogenesis in humans (23). Unfortunately, administration of most $\beta$-adrenergic agents is accompanied by a variety of potentially harmful side effects, such as hypertension, tachycardia, anxiety, and headaches. Possibly, increasing BAT activity through induction of this complex system via safe medicinal products, free of unbeneficial side effects, could be a future target for the prevention and treatment of obesity. Especially, the development and effects of $\beta 3$-receptor-specific agonists still needs further attention.

\section{Thyroid hormones}

In addition to direct sympathetic stimulation, endocrine stimulation also affects BAT thermogenesis in animals. The thyroid gland secretes the two forms of thyroid hormone, triiodothyronine and thyroxine ( $\mathrm{T} 3$ and $\mathrm{T} 4$, respectively). $\mathrm{T} 3$ and $\mathrm{T} 4$, which are known to play a key role in thermogenesis in humans, are secreted into the blood-stream in response to high circulating plasma levels of thyroid-stimulating hormone (TSH) or in response to cold (26). Ninety-five percent of the hormones secreted by the thyroid gland will be the inactive pro-hormone thyroxine (T4), that needs to be activated in target cells by deiodinases, forming the hormone triiodothyronine (T3). T3 has significant positive effect on energy expenditure in humans, as is illustrated by clinical states of hypo- or hyperthyroidism where energy expenditure respectively decreases or increases (27). In rodents, thyroid hormone has been known to be an activator of BAT. After conversion of T4 to T3 by the BAT-specific type 2 deiodinase (D2), thyroid hormone enhances thermogenesis in BAT (28) Figure 1.

This T3-mediated increase in energy expenditure occurs through binding of T3 on thyroid nuclear receptor TR $\alpha 1$ (thyroid receptor 1 alpha), found on brown adipocytes. Thyroid-stimulating hormone (TSH), secreted by thyrotrophic cells in the anterior pituitary gland, stimulates the thyroid gland to release T4. Interestingly, TSH itself also seems to be involved in thermogenesis. TSH receptor expression has been identified in a variety of cell types, including BAT in rats (29). This suggests interplay between TSH and thyroid hormones responsible for the thyroid effect on BAT function.

Recent studies have shown that treatment of human stem cells with T3 stimulates the development of UCP1-positive cells within white adipose tissue (30). Since UCP1 is the protein that facilitates mitochondrial uncoupling in BAT, this suggests thyroid hormone significantly affects 'browning' of WAT in humans.

Nevertheless, without thyroid stimulation BAT can still become active. When D2-deficient mice are exposed to cold, thermogenesis is still accomplished by stimulation via the sympathetic nervous system and the limited availability of active plasma thyroid hormone. However, when these animals are not exposed to cold, they develop glucose intolerance, non-alcoholic fatty liver disease (NAFLD), and diet-induced obesity (31). This suggests that thyroid-induced, D2-dependent BAT activity is important to prevent development of these diseases. 


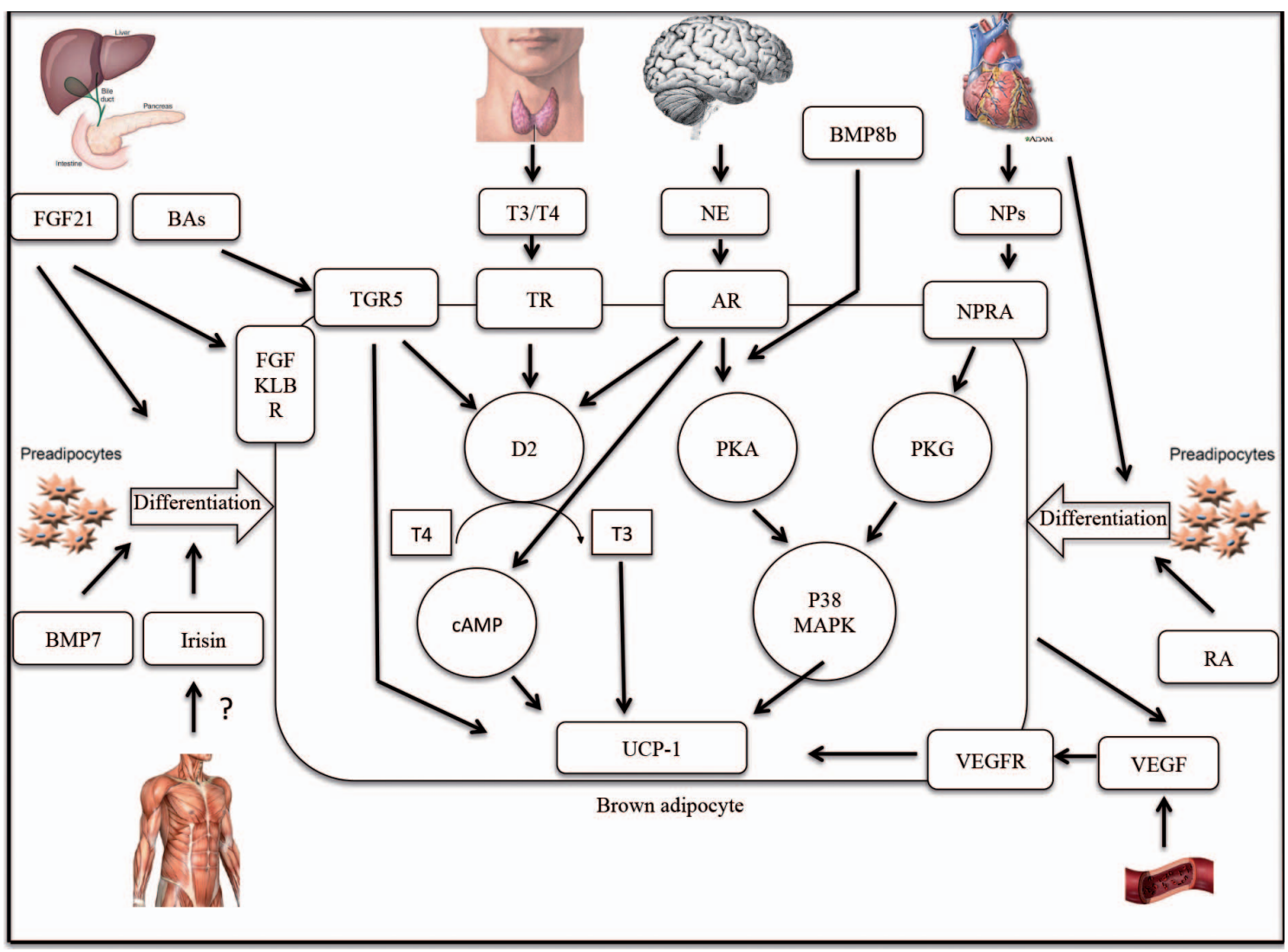

Figure 1. Molecular endogenous pathways regulating brown adipose tissue function. $\mathrm{AR}=$ adrenergic receptor; $\mathrm{BAs}=$ bile acids; $\mathrm{BMP7}=$ bone $\mathrm{morphogenetic}$ factor type 7; $c A M P=$ cyclic adenosine monophosphate; D2 = type 2 deiodinase; FGF21 = fibroblast growth factor 21; FGF-KLBR= fibroblast growth factor- Klotho- $\beta$ receptor; $\mathrm{NE}=$ norepinephrine; NPRA $=$ natriuretic peptide receptor; NPs = natriuretic peptides; 338 MAPK $=$ cytokinin specific binding protein mitogen-activated protein kinase; $\mathrm{PKA}=$ protein kinase $\mathrm{A} ; \mathrm{PKG}=$ cyclic guanosine monophosphate-dependent protein kinase; $\mathrm{RA}=$ retinoic acid; $\mathrm{T} 3=$ triiodothyronine; $\mathrm{T} 4=$ thyroxine; TGR5 $=$ transmembrane $\mathrm{G}$ protein-coupled receptor $5 ; \mathrm{TR}=$ thyroid hormone receptor; $\mathrm{UCP} 1=$ uncoupling protein $1 ; \mathrm{VEGF}=$ vascular endothelial growth factor; VEGFR = vascular endothelial growth factor receptor.

Besides the direct influence of thyroid hormone on the brown adipocyte, thyroid hormone could also induce BAT activity centrally by stimulating the hypothalamic pathway. In rats in a hyperthyroid state the excess thyroid hormone seems to alter hypothalamic AMPK (5' adenosine monophosphate-activated protein kinase)-dependent activation of de novo lipogenesis, resulting in increased dissipation of energy in BAT and associated weight loss (32). Thus, thyroid hormone seems to affect BAT activity both at cellular level during cold exposure and at the brain level regardless of temperature. A case report of a patient with extreme insulin resistance and thyroid gland cancer seems to support this theory. The therapeutic treatment of this condition with high doses of thyroid hormone was accompanied with active BAT on PET-CT, in the absence of a cold stimulus (33). Interestingly, thyroid hormone treatment also resolved the hyperglycemia of this patient, suggesting a role for BAT in glucose metabolism. In a larger study cohort, increased insulin resistance was associated with a D2 gene mutation. Moreover, if this D2 mutation was accompanied by a mutation in the $\beta 3$-adrenergic receptor, BMI (body mass index) was significantly higher (34).

In summary, the synergism between the sympathetic nervous system and thyroid axis seems to be of great importance in the control of BAT-mediated thermogenesis. During hypothyroidism, BAT activity could be impaired, which could lead to overweight and associated co-morbidities (e.g. insulin resistance). Therefore, BAT-targeted thyroid thermogenesis could be a target for obesity treatment (35).

\section{FNDC5/irisin}

Exercise is known for its beneficial effects on a variety of organ systems and is essential in weight loss strategies as a tool to burn off excess calories. Exercise leads to massive activation of the SNS, but it remains unclear whether this is accompanied by increased BAT activity. Several animal studies have addressed this issue, with ambiguous results. So far, most studies (36) found no excitatory effect of exercise on BAT activity, except for those cases where 6-week swimming training protocols were followed (37).

Recent insights in rodent studies have led to the conclusion that exercise does have stimulating effects on brown adipose tissue development. In 2012 exercise training was reported to result in browning of subcutaneous fat tissue. In this context, muscle has been identified as an endocrine organ releasing various cytokines (myokines) for the regulation of metabolic and physiological pathways (38). Irisin, first discovered in a mouse model, is a by-product of muscle proteolysis of FNDC5 (fibronectin type 3 containing 5), a membrane protein. After the release of irisin into the blood-stream, it is reported to exert hormone-like functions on WAT. Mice with overexpression of PGC1 $\alpha$, a transcriptional coactivator for several biological programs related to metabolism, were found to have increased browning in WAT from the inguinal area. Exercise is also known to lead to increased PGC1 $\alpha$ expression, and the effects of endurance training on browning of WAT were found to be similar. PGC1 $\alpha$-mediated expression of 
the membrane protein FNDC5 gene, and irisin, in muscle tissue (39) was shown to contribute to increased mRNA expression of PRDM16 and PGC1 $\alpha$, 'browning' and thermogenic capacity of subcutaneous white adipose tissue by increased UCP1 expression (5). This was observed in both adipocyte culture and in mouse models. Improved glucose tolerance was achieved in mice on a high-fat diet by adenovirus-mediated overexpression of liver FNDC5 mRNA and consequential 3-4-fold increase in plasma irisin levels (39).

Earlier studies had failed to provide equally successful results. Acute effects of running lead to a transient increase in SNS activity accompanied with heat production. However, long-term training studies found neither changes in total RNA content and UCP1 gene expression (40) nor reduction in BAT UCP1 expression (41). Furthermore, whole-body NST and blood flow to BAT did not differ between exercised and sedentary rats (36). Another study in human subjects showed no increase in FNDC5 mRNA in muscle biopsy tissue after exercise (42). A recent study provides evidence against a beneficial effect of irisin in humans. Genomic DNA, mRNA, and expressed sequence tags showed a mutation in the FNDC5 start codon, resulting in only $1 \%$ full-length protein. Furthermore, treatment of isolated human preadipocytes with both FNDC5 and irisin showed no effect on differentiation to brite adipocytes, suggesting that the positive association of irisin on the 'browning' of WAT that is observed in mice is unlikely to exist in humans (43).

In order to gain more insight in the physiological mechanisms in which irisin affects the human body, and especially human metabolism, prospective studies in human subjects are needed.

\section{Cardiac natriuretic peptides (ANP/BNP)}

A study from 2012 suggests that natriuretic peptides (NPs) are involved in the browning of white adipocytes in both mouse models and human subjects (44). NPs were first discovered in 1981, when they were known to be involved in hemodynamic homeostasis. Atrial natriuretic peptide (ANP) is a powerful vasodilatator, which is secreted by cells of the atria of the heart in response to high blood pressure and acts to reduce the water, sodium, and adipose loads on the circulatory system, thereby reducing blood pressure. Brain natriuretic peptide (BNP) is secreted by the ventricles of the heart in response to excessive stretching and decreases systemic vascular resistance and central venous pressure but increases natriuretic potential.

A recent review suggests that, besides regulation of blood pressure and blood volume, NPs might also be involved in energy homeostasis (45). In 2000 NPs were identified to play a role in lipolysis in human adipose tissue and increase plasma levels of non-esterified fatty acids. Treatment of adipocyte cultures from wild-type mice with ANPs showed increased lipolysis in these adipocytes. In human subjects undergoing ANP-infusion, similar rises in lipolysis rate were observed (46). Interestingly, plasma levels of NPs seem to be suppressed in obese subjects (47).

Also, circulating levels of NPs are negatively related to type 2 diabetes incidence, and some studies even identified low levels of NPs as a predictor for the development of this disease (48).

The study of Bordicchia et al. (44) demonstrated a thermogenic effect of NPs in mice and in human adipocytes differentiated from human multipotent adipose-derived stem cells. According to the findings in this study, the mechanism of increasing typical brown fat thermogenesis, as effective as catecholamine-induced BAT thermogenesis, works through activating guanylyl cyclase containing natriuretic peptide receptor A (NPRA), which in turn activates the second messenger cyclic guanosine monophosphate (cGMP). This second messenger activates cGMP-dependent protein kinase (PKG) (49), which is capable of phosphorylating key targets in the fat cell, like hormone-sensitive lipase (HSL) and perilipins (50). ANP-induced activation of AMPK enhanced mitochondrial capacity and treatment of differentiated multipotent adipose-derived stem cells with ANP lead to increased expression of UCP1, PGC1 $\alpha$, cytochrome c, and PRDM16 (44). The capacity of ANPs to modify the expression of these key regulators of the brown adipocyte phenotype has been shown to be comparable to that of the non-selective $\beta$-adrenergic receptor agonist isoproterenol and the $\beta 3$-adrenergic receptor agonist L755,507, the latter two being known for their high capacity to enhance the transcription of genes promoting the browning of adipocytes and genes involved in respiratory uncoupling in brown adipose tissue (44). BNP infusion in mice for a period of 7 days was associated with increased energy expenditure and browning of white adipose tissue (44). Also, in human subjects an increase in postprandial energy expenditure was observed after ANP infusion at a rate of $25 \mathrm{ng} / \mathrm{kg} / \mathrm{min}$ (51).

In conclusion, NPs are related to thermoregulation and negatively correlated to obesity and obesity-related metabolic diseases, like type 2 diabetes, in humans. In the future, NPs could be useful activators of BAT in the quest to prevent and treat the obesity epidemic.

\section{Insulin}

Insulin is known to be responsible for GLUT4 (glucose transporter type 4)-mediated glucose uptake in brown adipose tissue. For a long time lipid combustion was seen as the major fuel source for brown adipose tissue, but studies have shown that after UCP1 activation heat production in BAT is a resultant of both glucose and fat combustion (52). So besides fatty acids, glucose is taken up by BAT and can act as a fuel for mitochondrial uncoupling (3), leading to heat energy dissipation, weight loss, and lowered plasma glucose levels. Although fatty acid oxidation accounts for the major part of cold-induced thermogenesis in brown adipocytes, glucose metabolism is also high during cold exposure. Where free fatty acids are a necessity for activation of UCP1, once activated both lipids and carbohydrates are used as sources of fuel by this tissue. In fact, in isolated brown adipocytes glucose uptake and thermogenesis are closely linked (52), as demonstrated by the absence of norepinephrine-induced increase in glucose uptake in UCP1-ablated mice, which is evident in the presence of UCP1 (53). Besides acting as a fuel for BAT thermogenesis, glucose could also have anaplerotic effects and enhance the functioning of the Krebs cycle in the form of pyruvate, providing ATP for cell functioning (54).

Studies in genetically obese diabetic rodents showed that these animals have lower body temperature than lean non-diabetic controls, die of hypothermia upon cold exposure, and have only $50 \%$ of the BAT thermogenic capacities that normal animals have due to impaired BAT activity. Despite the similarities of these findings to results in studies with genetically obese but non-diabetic mice, some studies indicate that not the obesity per se but the accompanying insulin resistance is, at least partly, responsible for the reduction in non-shivering thermogenesis in BAT (55). In many animal models of obesity insulin resistance and defective BAT thermogenesis are clearly associated (56). However, a direct causation between reduced NST and insulin resistance was not proved. Recent human studies under thermoneutral conditions have confirmed the findings in animal studies and indicate reduced glucose uptake and BAT activity in obese and diabetic subjects (57). BAT activity was found to be negatively associated with plasma glucose values (58). Transplantation of BAT from donor mice to age- and sex-matched recipient mice resulted in 
beneficial effects on glucose tolerance, insulin sensitivity, body weight, and fat mass after 8-12 weeks. Furthermore, insulinsimulated glucose uptake in BAT, WAT, and heart muscle was improved (59). Rodent studies performed after fasting or after chronic administration of a high-fat diet, in which insulin levels are low or subjects have become insulin-resistant, respectively, also show reduced uptake of glucose in brown adipose tissue (3). Although recently the prevalence of $\left[{ }^{18} \mathrm{~F}\right] \mathrm{FDG}$-detected BAT was proven to be negatively associated with diabetes status (57), no acute positive effect of insulin on BAT respiration has been identified in vivo. Insulin might play a role in BAT thermogenic capacity by modulating the response of BAT to norepinephrine and controlling of mitochondrial uncoupling protein expression. Injection of insulin directly into the hypothalamus in mice increased BAT activity on PET-CT imaging, resulting in enhanced thermogenesis (60). Combining insulin injection with cold exposure was found to synergistically enhance glucose uptake in BAT (61). Furthermore, in UCP1-ablated mice glucose uptake in BAT was absent (53). A recent human study, with infusion of insulin into the blood-stream, has shown that BAT glucose uptake increased 5-fold compared to glucose-uptake in brown adipose tissue at baseline (62). However, no direct evidence of impaired BAT activity and BAT thermogenesis in diabetic human subjects is available. In order to obtain data on the full effect of insulin resistance on BAT thermogenic capacity BAT activity upon mild cold exposure in diabetic humans should be investigated. Also, it would be interesting to study the effect of insulin on BAT glucose uptake and effects on energy expenditure.

In conclusion, insulin can stimulate glucose uptake in BAT (at least in a thermoneutral environment). The development of interventions to promote insulin-stimulated glucose uptake in BAT could be a therapeutic target for obesity and diabetes.

\section{FGF21}

Fibroblast growth factors (FGFs) are heparin-binding proteins known as paracrine factors involved in in the control of cell growth and differentiation. The members of the FGF21 (fibroblast growth factor 21) subfamily (including FGF21, FGF19, and FGF23) differ from the other FGF proteins in that they have virtually no mitogenic effects (63). Also, they exert hormone-like functions, due to lack of the heparin-binding domain, which allows them to move freely from the tissue in which they are expressed to the circulation to act as systemic hormones.

Besides the involvement of FGFs in cell development and survival recent studies suggest a role for members of the FGF21 subfamily, and especially FGF21, in energy homeostasis. FGF21 (the factor, not the subfamily) is expressed for the main part in the liver, pancreas, skeletal muscle, but also WAT and BAT. FGF21 binds to the FGF receptor (FGFR) in target cells and activates them only in the presence of the $\beta$-Klotho transmembrane protein, which acts as a cofactor for efficient signaling (64). All positive metabolic effects of FGF21 diminished in whole-body and adipose tissueselective $\beta$-Klotho-knock-out mice, which demonstrates the requirement of tissue-specific expression of FGFR and $\beta$-Klotho as a cofactor in determining the extent of the metabolic activity by FGF21-FGF21 receptor interaction (65).

In 2005 the therapeutic potential of FGF21 in counteracting metabolic diseases associated with obesity was first described. Treatment of mouse adipocytes and also primary cultures of human adipocytes with FGF21 led to increased glucose uptake in these cells (66). Short-term administration of synthetic FGF21 to both obese, diabetic mice and rhesus monkeys has been shown to have profound effects. Plasma glucose levels were lowered, energy expenditure increased, and insulin sensitivity improved significantly (67). Long-term studies in diet-induced obese mice showed reversal of hepatic steatosis, decreased hepatic glucose production, and increased insulin-mediated uptake of glucose in the heart, adipose tissue, and skeletal muscle after treatment with recombinant FGF21 for 3-6 weeks (67).

Activation of fibroblast growth factor 21 (FGF21) is known to play an important role in free fatty acid (FFA) oxidation, lipolysis, and ketogenesis during fasting. Besides FGF21 expression in liver, WAT, skeletal muscle, and the pancreas, recently FGF21 expression has been identified in BAT (68). Treatment of neonatal BAT and isolated adipocytes with recombinant FGF21 promotes thermogenic activity. Systemic administration of FGF21 in mice leads to expression of thermogenic genes in BAT, associated with cold-induced thermogenesis, like UCP1 and type 2 deiodinase (69). Expression of these genes results in enhanced mitochondrial uncoupling in BAT mitochondria and enhanced conversion of the inactive T4 thyroid hormone into the active T3, also stimulating BAT activity. After cold exposure or selective $\beta$-adrenergic stimulation FGF21 is overexpressed in BAT, leading to the transcription of UCP1 and browning of WAT, by enhanced adipose tissue PGC1 $\alpha$ mRNA levels, which is a thermogenic coactivator leading to increased mitochondrial gene expression of UCP1 and oxidative function in BAT (70).

In a recent human study, augmented FGF21 levels correlated positively with NST (71). These results strongly suggest that FGF21 expression induces NST and could have beneficial effects on BAT activity.

Because FGF21 acts on and reverses aspects of the obesity metabolic profile, it has great potential as a therapeutic target for treatment of the metabolic syndrome in the future. However, FGF21 may cause bone loss due to enhanced differentiation of bone marrow mesenchymal stem cells to adipocytes instead of osteoblasts (72). Therefore more research is needed before FGF21 could be implemented as an anti-obesity drug. Also, the effect of FGF21 enhancement by cold exposure on BAT activity in humans should be investigated.

\section{Bile acids}

Recently, bile acids (BAs) have been implicated to play a role in energy metabolism and BAT functioning. BAs have long been known to be essential factors in lipid metabolism and cholesterol catabolism (73), the latter being the major route for elimination of surplus cholesterol from the body (74). Four major types of BAs are known: the primary BAs cholic acid (CA) and chenodeoxycholic acid (CDCA) and the secondary BAs deoxycholic acid (DCA) and lithocholic acid (LCA), which are converted from primary BAs by bacterial enzymes in the intestines (75).

BA metabolism has been implicated in the regulation of energy metabolism. BAs were shown to be natural ligands to the nuclear farnesoid X receptor (FXR) (76). This receptor controls the synthesis and enterohepatic circulation of BAs by adjusting the expression of a program of essential gene components that are involved in BA synthesis, transportation, conjugation, and detoxification (77). Recently, a study reported that FXR deficiency improves glucose homeostasis in a mouse model for the metabolic syndrome (78). Also, it was established that a synthetic FXR agonist (GW4064) deteriorates metabolic control in a diet-induced obesity mouse model (79). However, other studies show that BAs bind to the FXR receptor, stimulating FGF19 transcription, and several FXR/bile acid response elements have been identified in the FGF19 gene (80). FGF19 is a member of the fibroblast growth factor family, as described above (section 3.6), and has an important function as a hormone produced in the ileum in response to bile acid absorption. It is also known to regulate new bile 
acid synthesis, by acting through the FGFR4/Klotho- $\beta$ receptor complexes in the liver to inhibit CYP7A1 (cytochrome P450 7A1) (81). FGF19 also has metabolic effects, affecting glucose metabolism when used in experimental mouse models (82). These findings show that the FXR receptor might be involved in the pathogenesis of metabolic syndrome.

BAs may also exert their function in peripheral tissues through another pathway involving TGR5 (transmembrane G proteincoupled receptor 5). A recent study demonstrated increased EE in mice by oral ingestion of cholic acid, through BA binding to and activation of TGR5, a G-protein-coupled receptor (73). In BAT of mice and in human skeletal myocyte cultures, TGR5 activation stimulated intracellular cAMP formation and activated D2. D2 in turn converts the inactive thyroid hormone T4 (thyroxine) into the active T3 (3,5,5-triiodo-I-thyronine) and stimulates energy expenditure in BAT (in rodents) and in skeletal muscle (in humans) (described above in section 3.2) (73). Human evidence for this suggestion is still limited and only a few studies have investigated the relationship between BA and EE in humans. One study (83) found positive relations between circulating BAs and EE in a small group of healthy volunteers $(n=10)$. Another study (84) found no significant effect of the BA sequestrant colesevelam for 8 weeks on resting EE.

In summary, the interplay between BAs and the thyroid axis might be of importance for BAT activity. However, no prospective studies have confirmed the strong relation between circulating BAs and BAT activity, as was observed in rodents, in humans yet. In order to develop new ways to target the obesity pandemic, future studies should address the interplay between bile acids and the thyroid axis and the possible beneficial effects of activating this pathway on EE and BAT activities in humans.

\section{Bone morphogenetic proteins (BMPs)}

Bone morphogenetic factors (BMPs) are another group of novel promising targets for BAT-targeted anti-obesity therapy. BMPs belong to the transforming growth factor $\beta$ (TGF- $\beta$ ) superfamily (85), and different BMPs are known to act on specific cell types (86). In mice, BMP2 and BMP4 are known to stimulate white adipogenesis, by stimulating the commitment of mesenchymal cells to the adipocyte lineage and by driving preadipocyte differentiation into mature white adipocytes (87). BMP7 and BMP8b are involved in BAT functioning. BMP7 promotes brown-fat differentiation in multipotent mesenchymal cells (88), and BMP8b is described to play a role in the direct regulation of thermogenesis (89). Mature brown adipocytes produce BMP8b in an attempt to amplify BAT thermogenic action in response to peripheral adrenergic activation. Strikingly, BMP8b is also expressed by the hypothalamus and acts centrally, increasing sympathetic output to BAT (89). Human evidence for a role of BMPs in BAT functioning and differentiation is currently still lacking.

More research on pathways and mechanisms in which BMP8b can specifically increase energy dissipation by BAT is needed.

\section{Retinoic acid}

Recently the potential for adipocyte plasticity in terms of characteristics specific to white or brown adipocytes remains under investigation. One of the factors of interest is retinoids. Retinoids are vitamin A (retinol) and $\beta$-carotene metabolites, with diverse biological functions, like development, immune function, and vision (90). They have recently been linked to energy homeostasis and adipogenesis control. Retinoic acid, which is formed from the vitamin A derivative retinaldehyde (Rald), activates the retinoic acid receptor (RAR) and retinoid X receptor (RXR), regulating gene expression in mice (91), adipocyte differentiation, and metabolism. Recent work showed that retinoids can act as inducers of UCP1 gene expression within WAT in obese mice through RAR and PGC1 $\alpha$ (92), associated with increased mitochondrial oxidative capacity. Furthermore, MEF (mouse embryonic fibroblast)-derived adipocytes exhibited high mRNA expression of PRDM16 (93), which is known as one of the main transcriptional co-regulators controlling the development of brown adipocytes (4).

The finding that retinoids regulate a thermogenic program in WAT may have implications for future research on adipocyte differentiation and UCP1 gene expression in human adipose cells. Furthermore, these results may help elucidating the signaling pathways of the UCP1 gene in an attempt to find ways for stimulation of adaptive thermogenesis, with potential therapeutic implications.

\section{Vascular endothelial growth factor (VEGF)}

Recent insights have suggested a role for vascular endothelial growth (VEGF) in BAT functioning. VEGF is a family of signal proteins that stimulate vasculogenesis and angiogenesis. The VEGF family includes VEGF-A, VEGF-B, VEGF-C, VEGF-D, VEGF-E, and placental growth factor (PIGF) (94). Normally these factors are released in response to hypoxia, but recent studies indicate that VEGF is released from adipose tissue in response to cold, in a process to facilitate oxygen delivery and to promote heat exchange. The VEGF-A member is known to be associated with embryonic development. Furthermore, this subtype is highly expressed in adipose tissue and seems to be related to obesity (95). The B-type VEGF is involved in energy metabolism regulation and has recently been found to regulate fatty acid transport proteins through VEGF receptor 1 and neuropilin. VEGF-B knock-out mice have been associated with decreased fat accumulation in BAT and increased deposition in WAT (96). In a recent study (97) a genetic mouse model of repressed VEGF-A was used to study VEGF-regulated energy metabolism in white adipose tissue. VEGF repression seemed to be associated with lower food efficiency, lower body weight, and resistance to high-fat-diet-induced obesity. Furthermore, development of brown-like adipocytes within WAT took place in VEGF-repressed mice, with up-regulation of BAT-specific genes like PRDM16, BMP7, and UCP1 and down-regulation of WAT-specific genes like, leptin suggesting a role for VEGF in the differentiation of WAT into BAT. Another recent study showed that VEGF expression increases concomitantly with brown adipocyte differentiation (98). In cultured brown adipocytes VEGF promoted cell survival and proliferation. VEGF-A repression was accompanied by up-regulation of VEGF-B.

VEGF-A overexpression in mouse adipose tissue promotes a 'BAT-like' phenotype in WAT depots, accompanied by increased BAT PGC1 $\alpha$ and UCP1 expression, potentiating increased thermogenesis and energy expenditure. Human evidence is lacking and human studies on VEGF effects on BAT functioning are needed. VEGF-A and VEGF-B seem to be counteractively working against each other in energy balance metabolism, and this topic should receive more scientific attention in the future in order to elucidate the mechanisms by which VEGFs are involved in adipose tissue metabolism.

\section{Perspective and therapeutic/clinical impact}

Currently, brown adipose tissue is recognized as a potential weight loss inducer. Especially ways to activate BAT from inside the body, via endogenous substances and hormones, have recently attracted the attention of research groups throughout the world. Involvement of the sympathetic nervous system, thyroid 
hormones, FNDC5/irisin, cardiac natriuretic peptides, insulin, FGF21, bile acids, BMPs, retinoic acid, and VEGFs in BAT activity and 'browning' of WAT in humans has been discussed. Besides the direct effects these factors seem to have on BAT activity and 'browning' of WAT in humans, some of them appear to be interconnected.

The different adrenergic receptors in the sympathetic nervous system work synergistically to activate BAT. Stimulation of the serotonin receptor potentiates BAT response to glutamate, markedly increasing sympathetic activation of BAT (20). BAT activation through thyroid hormone is also under influence of the SNS system. The presence of D2 in BAT, which potentiates conversion of $\mathrm{T} 4$ into the metabolically active $\mathrm{T} 3$, is under direct control of norepinephrine. Furthermore, thyroid hormone seems to be a direct inducer of hypothalamic AMPK, which leads to enhanced SNS activation and de novo lipogenesis, resulting in increased energy dissipation in BAT (32). Moreover, treatment of human stem cells with T3 stimulated the development of UCP1positive cells within WAT, suggesting a role for thyroid hormone in 'browning' of white adipose tissue.

Besides this SNS-thyroid hormone synergism, SNS activation also seems to be related to exercise, and associated irisin release, since exercise leads to massive SNS activation (99). However, most studies did not find accompanying increase in BAT activity, and a recently published study seems to provide evidence against a beneficial effect of irisin on BAT functioning in humans (43).

Cardiac natriuretic peptides could also potentially enhance BAT functioning. BNP infusion in mice was associated with increased energy expenditure and 'browning' of WAT (39). In humans, circulating levels of NPs are negatively related to type 2 diabetes incidence (100) and BMI (101), suggesting a protective role in the development of obesity and associated metabolic diseases.

In many animal models of obesity insulin resistance and defective BAT thermogenesis are clearly associated (56), but a direct causation between reduced NST and insulin resistance has never been proved in humans. Recent studies in human diabetic subjects found a negative association between BAT activity and plasma glucose values in human subjects (57). Administration of FGF21 to obese and diabetic mice seems to reduce elevated plasma glucose values by increasing insulin sensitivity and glucose uptake in adipose tissue and enhanced energy expenditure (67). Furthermore, systemic administration of FGF21 to mice leads to the expression of thermogenic genes, like UCP1 and D2 (28). FGF21-mediated D2 expression suggests a link of the FGF21 pathway and the thyroid axis in the activation of BAT.

Recently another thyroid axis interaction was discovered. BA binding to the TGR5 receptor stimulates intracellular activation of D2, leading to activation of thyroid hormone and increased energy expenditure in rodent BAT and human skeletal muscle (73).

In mice, lately some other factors that may be involved in BAT functioning were identified. BMP7 is known to promote brown fat differentiation in multipotent mesenchymal cells, and BMP8b works both peripherally and centrally, increasing both BAT responses to adrenergic stimuli and sympathetic output to BAT. Other novel factors implicated in regulation of a thermogenic program in WAT are retinoids and VEGF. In obese mice, retinoic acid acts as an inducer of UCP1 gene expression within WAT. Furthermore, this vitamin A derivative seems to promote the expression of transcriptional co-regulators in the development of brown adipocytes, like PRDM16. VEGF appears to be involved in the development of the BAT-specific genes PRDM16, BMP7, and UCP1 in WAT, suggesting a role for VEGF in the differentiation of WAT into BAT. More attention on the development and regulation of the BAT thermogenic program in WAT by these factors is needed. Even though the evidence in rodents points toward involvement of these factors in BAT functioning, human data are still lacking. Human studies are needed to assess the mechanisms by which these novel endogenous factors have implications for BAT-targeted anti-obesity treatment.

The interplay between the different pathways described in this review points towards the need to target not only specific factors but to take into account these interactions. In rodents, activation of BAT through stimulation of some of these pathways has already been found to be effective. However, human evidence for effective methods of BAT activation is still lacking. Novel approaches for BAT activation as possible treatment options for obesity should be investigated in large human clinical trials.

Declaration of interest: Supported by the Netherlands Organization for Scientific Research (TOP 91209037 to W.D.v.M.L.) and the EU FP7 project DIABAT (HEALTH-F2-2011-278373). The authors report no conflicts of interest.

\section{References}

1. Brown WV, Fujioka K, Wilson PW, Woodworth KA. Obesity: why be concerned? Am J Med. 2009;122(4 Suppl 1):S4-11.

2. van Marken Lichtenbelt WD, Schrauwen P. Implications of nonshivering thermogenesis for energy balance regulation in humans. Am J Physiol Regul Integr Comp Physiol. 2011;301:R285-296.

3. Cannon B, Nedergaard J. Brown adipose tissue: function and physiological significance. Physiol Rev. 2004;84:277-359.

4. Seale P, Bjork B, Yang W, Kajimura S, Chin S, Kuang S, et al. PRDM16 controls a brown fat/skeletal muscle switch. Nature. 2008;454:961-7.

5. Puigserver P, Wu Z, Park CW, Graves R, Wright M, Spiegelman BM. A cold-inducible coactivator of nuclear receptors linked to adaptive thermogenesis. Cell. 1998;92:829-39.

6. van der Lans AA, Hoeks J, Brans B, Vijgen GH, Visser MG, Vosselman $\mathrm{MJ}$, et al. Cold acclimation recruits human brown fat and increases nonshivering thermogenesis. J Clin Invest. 2013;123:3395-403.

7. Yeung HW, Grewal RK, Gonen M, Schoder H, Larson SM. Patterns of (18)F-FDG uptake in adipose tissue and muscle: a potential source of false-positives for PET. J Nucl Med. 2003;44:1789-96.

8. Virtanen KA, Lidell ME, Orava J, Heglind M, Westergren R, Niemi T, et al. Functional brown adipose tissue in healthy adults. N Engl J Med. 2009;360:1518-25.

9. van Marken Lichtenbelt WD, Vanhommerig JW, Smulders NM, Drossaerts JM, Kemerink GJ, Bouvy ND, et al. Cold-activated brown adipose tissue in healthy men. N Engl J Med. 2009;360:1500-8.

10. Fink C, Krissak R, Henzler T, Lechel U, Brix G, Takx RA, et al. Radiation dose at coronary CT angiography: second-generation dual-source CT versus single-source 64-MDCT and first-generation dual-source CT. AJR. Am J Roentgenol. 2011;196:W550-7.

11. Admiraal WM, Holleman F, Bahler L, Soeters MR, Hoekstra JB, Verberne HJ. Combining 123I-metaiodobenzylguanidine SPECT/CT and 18F-FDG PET/CT for the assessment of brown adipose tissue activity in humans during cold exposure. J Nucl Med. 2013;54:208-12.

12. Branca RT, Zhang L, Warren WS, Auerbach E, Khanna A, Degan S, et al. In vivo noninvasive detection of brown adipose tissue through intermolecular zero-quantum MRI. PLoS One. 2013;8:e74206.

13. $\mathrm{Hu} \mathrm{HH}$, Yin L, Aggabao PC, Perkins TG, Chia JM, Gilsanz V. Comparison of brown and white adipose tissues in infants and children with chemical-shift-encoded water-fat MRI. J Magn Reson Imaging. 2013;38:885-96.

14. Yoneshiro T, Aita S, Matsushita M, Kayahara T, Kameya T, Kawai Y, et al. Recruited brown adipose tissue as an antiobesity agent in humans. J Clin Invest. 2013;123:3404-8.

15. Chen KY, Brychta RJ, Linderman JD, Smith S, Courville A, Dieckmann $\mathrm{W}$, et al. Brown fat activation mediates cold-induced thermogenesis in adult humans in response to a mild decrease in ambient temperature. J Clin Endocrinol Metab. 2013;98:E1218-23.

16. Morrison SF, Nakamura K. Central neural pathways for thermoregulation. Front Biosci (Landmark Ed). 2011;16:74-104.

17. Collins S, Yehuda-Shnaidman E, Wang H. Positive and negative control of Ucp 1 gene transcription and the role of beta-adrenergic signaling networks. Int J Obes (Lond). 2010;34(Suppl 1):S28-33. 
18. Vaughan $\mathrm{CH}$, Bartness TJ. Anterograde transneuronal viral tract tracing reveals central sensory circuits from brown fat and sensory denervation alters its thermogenic responses. Am J Physiol Regul Integr Comp Physiol. 2012;302:R1049-58.

19. Nakamura K, Matsumura K, Hubschle T, Nakamura Y, Hioki H, Fujiyama F, et al. Identification of sympathetic premotor neurons in medullary raphe regions mediating fever and other thermoregulatory functions. J Neurosci. 2004;24:5370-80.

20. Madden CJ, Morrison SF. Serotonin potentiates sympathetic responses evoked by spinal NMDA. J Physiol. 2006;577:525-37.

21. Madden CJ, Morrison SF. Endogenous activation of spinal 5-hydroxytryptamine $(5-\mathrm{HT})$ receptors contributes to the thermoregulatory activation of brown adipose tissue. Am J Physiol Regul Integr Comp Physiol. 2010;298:R776-83.

22. Yamaga LY, Thom AF, Wagner J, Baroni RH, Hidal JT, Funari MG. The effect of catecholamines on the glucose uptake in brown adipose tissue demonstrated by (18)F-FDG PET/CT in a patient with adrenal pheochromocytoma. Eur J Nucl Med Mol Imaging. 2008;35:446-7.

23. Parysow O, Mollerach AM, Jager V, Racioppi S, San Roman J, Gerbaudo VH. Low-dose oral propranolol could reduce brown adipose tissue F-18 FDG uptake in patients undergoing PET scans. Clin Nucl Med. 2007;32:351-7.

24. Cypess AM, Chen YC, Sze C, Wang K, English J, Chan O, et al. Cold but not sympathomimetics activates human brown adipose tissue in vivo. Proc Natl Acad Sci U S A. 2012;109:10001-5.

25. Vosselman MJ, van der Lans AA, Brans B, Wierts R, van Baak MA, Schrauwen P, et al. Systemic beta-adrenergic stimulation of thermogenesis is not accompanied by brown adipose tissue activity in humans. Diabetes. 2012;61:3106-13.

26. Arancibia S, Rage F, Astier H, Tapia-Arancibia L. Neuroendocrine and autonomous mechanisms underlying thermoregulation in cold environment. Neuroendocrinology. 1996;64:257-67.

27. Bianco AC, Salvatore D, Gereben B, Berry MJ, Larsen PR. Biochemistry, cellular and molecular biology, and physiological roles of the iodothyronine selenodeiodinases. Endocr Rev. 2002;23:38-89.

28. de Jesus LA, Carvalho SD, Ribeiro MO, Schneider M, Kim SW, Harney JW, et al. The type 2 iodothyronine deiodinase is essential for adaptive thermogenesis in brown adipose tissue. J Clin Invest. 2001;108:137985.

29. Williams GR. Extrathyroidal expression of TSH receptor. Ann Endocrinol (Paris). 2011;72:68-73.

30. Lee JY, Takahashi N, Yasubuchi M, Kim YI, Hashizaki H, Kim MJ, et al. Triiodothyronine induces UCP1 expression and mitochondrial biogenesis in human adipocytes. Am J Physiol Cell Physiol.2012;302:C46372.

31. Castillo M, Hall JA, Correa-Medina M, Ueta C, Kang HW, Cohen DE, et al. Disruption of thyroid hormone activation in type 2 deiodinase knockout mice causes obesity with glucose intolerance and liver steatosis only at thermoneutrality. Diabetes. 2011;60:1082-9.

32. Lopez M, Varela L, Vazquez MJ, Rodríguez-Cuenca S, González CR, Velagapudi VR, et al. Hypothalamic AMPK and fatty acid metabolism mediate thyroid regulation of energy balance. Nat Med. 2010;16:1001-8.

33. Skarulis MC, Celi FS, Mueller E, Zemskova M, Malek R, Hugendubler $\mathrm{L}$, et al. Thyroid hormone induced brown adipose tissue and amelioration of diabetes in a patient with extreme insulin resistance. J Clin Endocrinol Metab. 2010;95:256-62.

34. Mentuccia D, Proietti-Pannunzi L, Tanner K, Bacci V, Pollin TI, Poehlman ET, et al. Association between a novel variant of the human type 2 deiodinase gene Thr92Ala and insulin resistance: evidence of interaction with the Trp64Arg variant of the beta-3-adrenergic receptor. Diabetes. 2002;51:880-3.

35. Cannon B, Nedergaard J. Thyroid hormones: igniting brown fat via the brain. Nat Med. 2010;16:965-7.

36. Wickler SJ, Stern JS, Glick Z, Horwitz BA. Thermogenic capacity and brown fat in rats exercise-trained by running. Metabolism. 1987;36:76-81.

37. Oh-ishi S, Kizaki T, Toshinai K, Haga S, Fukuda K, Nagata N, et al. Swimming training improves brown-adipose-tissue activity in young and old mice. Mech Ageing Dev. 1996;89:67-78.

38. Pedersen BK, Febbraio MA. Muscles, exercise and obesity: skeletal muscle as a secretory organ. Nat Rev Endocrinol. 2012;8:457-65.

39. Bostrom P, Wu J, Jedrychowski MP, Korde A, Ye L, Lo JC, et al. A PGC1alpha-dependent myokine that drives brown-fat-like development of white fat and thermogenesis. Nature. 2012;481:463-8.

40. Segawa M, Oh-Ishi S, Kizaki T, Ookawara T, Sakurai T, Izawa T, et al. Effect of running training on brown adipose tissue activity in rats: a reevaluation. Res Commun Mol Pathol Pharmacol. 1998;100:77-82.
41. Scarpace PJ, Yenice S, Tumer N. Influence of exercise training and age on uncoupling protein mRNA expression in brown adipose tissue. Pharmacol Biochem Behav. 1994;49:1057-9.

42. Timmons JA, Baar K, Davidsen PK, Atherton PJ. Is irisin a human exercise gene? Nature. 2012;488:E9-10; discussion E10-11.

43. Raschke S, Elsen M, Gassenhuber H, Sommerfeld M, Schwahn U, Brockmann B, et al. Evidence against a beneficial effect of irisin in humans. PLoS One. 2013;8:e73680.

44. Bordicchia M, Liu D, Amri EZ, Ailhaud G, Dessì-Fulgheri P, Zhang C, et al. Cardiac natriuretic peptides act via $\mathrm{p} 38$ MAPK to induce the brown fat thermogenic program in mouse and human adipocytes. J Clin Invest. 2012;122:1022-36.

45. Moro C, Lafontan M. Natriuretic peptides and cGMP signaling control of energy homeostasis. Am J Physiol Heart Circ Physiol. 2013;304:H358-68.

46. Birkenfeld AL, Boschmann M, Moro C, Adams F, Heusser K, Franke $\mathrm{G}$, et al. Lipid mobilization with physiological atrial natriuretic peptide concentrations in humans. J Clin Endocrinol Metab. 2005;90:3622-8.

47. Das SR, Drazner MH, Dries DL, Vega GL, Stanek HG, Abdullah SM, et al. Impact of body mass and body composition on circulating levels of natriuretic peptides: results from the Dallas Heart Study. Circulation. 2005;112:2163-8.

48. Magnusson M, Jujic A, Hedblad B, Engström G, Persson M, Struck J, et al. Low plasma level of atrial natriuretic peptide predicts development of diabetes: the prospective Malmo Diet and Cancer study. J Clin Endocrinol Metab. 2012;97:638-45.

49. Sengenes C, Bouloumie A, Hauner H, Berlan M, Busse R, Lafontan M, et al. Involvement of a cGMP-dependent pathway in the natriuretic peptide-mediated hormone-sensitive lipase phosphorylation in human adipocytes. J Biol Chem. 2003;278:48617-26.

50. Carmen GY, Victor SM. Signalling mechanisms regulating lipolysis. Cell Signal. 2006;18:401-8.

51. Birkenfeld AL, Budziarek P, Boschmann M, Moro C, Adams F, Franke G, et al. Atrial natriuretic peptide induces postprandial lipid oxidation in humans. Diabetes. 2008;57:3199-204.

52. Cannon B, Nedergaard J. Metabolic consequences of the presence or absence of the thermogenic capacity of brown adipose tissue in mice (and probably in humans). Int J Obes (Lond). 2010;34(Suppl 1):S7-16.

53. Inokuma $\mathrm{K}$, Ogura-Okamatsu $\mathrm{Y}$, Toda $\mathrm{C}$, Kimura $\mathrm{K}$, Yamashita $\mathrm{H}$, Saito M. Uncoupling protein 1 is necessary for norepinephrineinduced glucose utilization in brown adipose tissue. Diabetes. 2005;54:1385-91.

54. Cannon B, Nedergaard J. The physiological role of pyruvate carboxylation in hamster brown adipose tissue. Eur J Biochem. 1979;94: $419-26$.

55. Marette A, Deshaies Y, Collet AJ, Tulp O, Bukowiecki LJ. Major thermogenic defect associated with insulin resistance in brown adipose tissue of obese diabetic SHR/N-cp rats. Am J Physiol. 1991;261(2 Pt 1):E204-13.

56. Himms-Hagen J. Brown adipose tissue thermogenesis and obesity. Prog Lipid Res. 1989;28:67-115.

57. Ouellet V, Routhier-Labadie A, Bellemare W, Lakhal-Chaieb L, Turcotte E, Carpentier AC, et al. Outdoor temperature, age, sex, body mass index, and diabetic status determine the prevalence, mass, and glucose-uptake activity of 18F-FDG-detected BAT in humans. J Clin Endocrinol Metab. 2011;96:192-9.

58. Jacene HA, Cohade CC, Zhang Z, Wahl RL. The relationship between patients' serum glucose levels and metabolically active brown adipose tissue detected by PET/CT. Mol Imaging Biol. 2011;13:1278-83.

59. Stanford KI, Middelbeek RJ, Townsend KL, An D, Nygaard EB, Hitchcox KM, et al. Brown adipose tissue regulates glucose homeostasis and insulin sensitivity. J Clin Invest. 2013;123:215-23.

60. Sanchez-Alavez M, Tabarean IV, Osborn O, Mitsukawa K, Schaefer J, Dubins J, et al. Insulin causes hyperthermia by direct inhibition of warm-sensitive neurons. Diabetes. 2010;59:43-50.

61. Vallerand AL, Perusse F, Bukowiecki LJ. Cold exposure potentiates the effect of insulin on in vivo glucose uptake. Am J Physiol. 1987;253(2 Pt 1):E179-86.

62. Orava J, Nuutila P, Lidell ME, Oikonen V, Noponen T, Viljanen T, et al. Different metabolic responses of human brown adipose tissue to activation by cold and insulin. Cell Metab. 2011;14:272-9.

63. Nishimura T, Nakatake $\mathrm{Y}$, Konishi M, Itoh N. Identification of a novel FGF, FGF-21, preferentially expressed in the liver. Biochim Biophys Acta. 2000;1492:203-6.

64. Kharitonenkov A, Dunbar JD, Bina HA, Bright S, Moyers JS, Zhang C, et al. FGF-21/FGF-21 receptor interaction and activation is determined by betaKlotho. J Cell Physiol. 2008;215:1-7. 
65. Ding X, Boney-Montoya J, Owen BM, Bookout AL, Coate KC, Mangelsdorf DJ, et al. betaKlotho is required for fibroblast growth factor 21 effects on growth and metabolism. Cell Metab. 2012;16:387-93.

66. Kharitonenkov A, Shiyanova TL, Koester A, Ford AM, Micanovic R, Galbreath EJ, et al. FGF-21 as a novel metabolic regulator. J Clin Invest. 2005; 115:1627-35.

67. Xu J, Lloyd DJ, Hale C, Stanislaus S, Chen M, Sivits G, et al. Fibroblast growth factor 21 reverses hepatic steatosis, increases energy expenditure, and improves insulin sensitivity in diet-induced obese mice. Diabetes. 2009;58:250-9.

68. Hondares E, Iglesias R, Giralt A, , Gonzalez FJ, Giralt M, Mampel T, et al. Thermogenic activation induces FGF21 expression and release in brown adipose tissue. J Biol Chem. 2011;286:12983-90.

69. Canto C, Auwerx J. Cell biology. FGF21 takes a fat bite. Science. 2012;336:675-6.

70. Wu Z, Puigserver P, Andersson U, Zhang C, Adelmant G, Mootha V, et al. Mechanisms controlling mitochondrial biogenesis and respiration through the thermogenic coactivator PGC-1. Cell. 1999;98: $115-24$.

71. Lee P, Brychta RJ, Linderman J, Smith S, Chen KY, Celi FS. Mild cold exposure modulates fibroblast growth factor 21 (FGF21) diurnal rhythm in humans: relationship between FGF21 levels, lipolysis, and cold-induced thermogenesis. J Clin Endocrinol Metab. 2013;98:E98-102.

72. Wei W, Dutchak PA, Wang X, Ding X, Wang X, Bookout AL, et al. Fibroblast growth factor 21 promotes bone loss by potentiating the effects of peroxisome proliferator-activated receptor gamma. Proc Natl Acad Sci U S A. 2012;109:3143-8.

73. Watanabe M, Houten SM, Mataki C, Christoffolete MA, Kim BW, Sato $\mathrm{H}$, et al. Bile acids induce energy expenditure by promoting intracellular thyroid hormone activation. Nature. 2006;439:484-9.

74. Chen X, Lou G, Meng Z, Huang W. TGR5: a novel target for weight maintenance and glucose metabolism. Exp Diabetes Res. 2011;2011:853501.

75. Bernstein H, Bernstein C, Payne CM, Dvorakova K, Garewal H. Bile acids as carcinogens in human gastrointestinal cancers. Mutat Res. 2005;589:47-65.

76. Lefebvre P, Cariou B, Lien F, Kuipers F, Staels B. Role of bile acids and bile acid receptors in metabolic regulation. Physiol Rev. 2009;89:147-91.

77. Russell DW. The enzymes, regulation, and genetics of bile acid synthesis. Annu Rev Biochem. 2003;72:137-74.

78. Prawitt J, Abdelkarim M, Stroeve JH, Popescu I, Duez H, Velagapudi VR, et al. Farnesoid X receptor deficiency improves glucose homeostasis in mouse models of obesity. Diabetes. 2011;60:1861-71.

79. Watanabe M, Horai Y, Houten SM, Morimoto K, Sugizaki T, Arita E, et al. Lowering bile acid pool size with a synthetic farnesoid X receptor (FXR) agonist induces obesity and diabetes through reduced energy expenditure. J Biol Chem. 2011;286:26913-20.

80. Miyata M, Hata T, Yamakawa H, Kagawa T, Yoshinari K, Yamazoe Y. Involvement of multiple elements in FXR-mediated transcriptional activation of FGF19. J Steroid Biochem Mol Biol. 2012;132:41-7.

81. Wu X, Ge H, Gupte J, Weiszmann J, Shimamoto G, Stevens J, et al. Co-receptor requirements for fibroblast growth factor-19 signaling. J Biol Chem. 2007;282:29069-72.

82. Tomlinson E, Fu L, John L, Hultgren B, Huang X, Renz M, et al. Transgenic mice expressing human fibroblast growth factor-19 display increased metabolic rate and decreased adiposity. Endocrinology. 2002;143:1741-7.

83. Ockenga J, Valentini L, Schuetz T, Wohlgemuth F, Glaeser S, Omar A, et al. Plasma bile acids are associated with energy expenditure and thyroid function in humans. J Clin Endocrinol Metab. 2012;97:535-42.

84. Brufau G, Bahr MJ, Staels B, Claudel T, Ockenga J, Böker KH, et al. Plasma bile acids are not associated with energy metabolism in humans. Nutr Metab (Lond). 2010;7:73.

85. Wozney JM, Rosen V, Celeste AJ, Mitsock LM, Whitters MJ, Kriz RW, et al. Novel regulators of bone formation: molecular clones and activities. Science. 1988;242:1528-34.

86. Chen D, Zhao M, Mundy GR. Bone morphogenetic proteins. Growth Factors. 2004;22:233-41.

87. Tang QQ, Otto TC, Lane MD. Commitment of C3H10T1/2 pluripotent stem cells to the adipocyte lineage. Proc Natl Acad Sci U S A. 2004;101:9607-11.

88. Tseng YH, Kokkotou E, Schulz TJ, Huang TL, Winnay JN, Taniguchi $\mathrm{CM}$, et al. New role of bone morphogenetic protein 7 in brown adipogenesis and energy expenditure. Nature. 2008;454:1000-4.

89. Whittle AJ, Carobbio S, Martins L, Slawik M, Hondares E, Vázquez MJ, et al. BMP8B increases brown adipose tissue thermogenesis through both central and peripheral actions. Cell. 2012;149:871-85.

90. Napoli JL. Retinoic acid: its biosynthesis and metabolism. Prog Nucleic Acid Res Mol Biol. 1999;63:139-88.

91. Ziouzenkova O, Plutzky J. Retinoid metabolism and nuclear receptor responses: new insights into coordinated regulation of the PPAR-RXR complex. FEBS Lett. 2008;582:32-38.

92. Kiefer FW, Vernochet C, O’Brien P, Spoerl S, Brown JD, Nallamshetty $\mathrm{S}$, et al. Retinaldehyde dehydrogenase 1 regulates a thermogenic program in white adipose tissue. Nat Med. 2012;18:918-25.

93. Mercader J, Palou A, Bonet ML. Induction of uncoupling protein-1 in mouse embryonic fibroblast-derived adipocytes by retinoic acid. Obesity (Silver Spring). 2010;18:655-62.

94. Holmes DI, Zachary I. The vascular endothelial growth factor (VEGF) family: angiogenic factors in health and disease. Genome Biol. 2005;6:209.

95. Cao Y. Angiogenesis modulates adipogenesis and obesity. J Clin Invest. 2007;117:2362-8.

96. Hagberg CE, Falkevall A, Wang X, Larsson E, Huusko J, Nilsson I, et al. Vascular endothelial growth factor B controls endothelial fatty acid uptake. Nature. 2010;464:917-21.

97. Lu X, Ji Y, Zhang L, Zhang Y, Zhang S, An Y, et al. Resistance to obesity by repression of VEGF gene expression through induction of brown-like adipocyte differentiation. Endocrinology. 2012;153: 3123-32.

98. Bagchi M, Kim LA, Boucher J, Walshe TE, Kahn CR, D’Amore PA. Vascular endothelial growth factor is important for brown adipose tissue development and maintenance. FASEB J. 2013;27:3257-71.

99. Christensen NJ, Galbo H. Sympathetic nervous activity during exercise. Annu Rev Physiol. 1983;45:139-53.

100. Wang TJ, Larson MG, Keyes MJ, Levy D, Benjamin EJ, Vasan RS. Association of plasma natriuretic peptide levels with metabolic risk factors in ambulatory individuals. Circulation. 2007;115:1345-53.

101. Sugisawa T, Kishimoto I, Kokubo Y, Makino H, Miyamoto Y, Yoshimasa Y. Association of plasma B-type natriuretic peptide levels with obesity in a general urban Japanese population: the Suita Study. Endocr J. 2010;57:727-33. 